\title{
Influence of soil conditions on the stochastic response of asphaltic lining dams to spatially varying ground motions
}

\author{
K. Hacıefendioğlu* \\ Karadeniz Technical University, Department of Civil Engineering, Trabzon, Turkey
}

\begin{abstract}
The effect of deconvolved stochastic seismic excitation on nonlinear dynamic response of dam-foundation interaction systems is investigated by using the equivalent linear method. For this purpose, three different earthquake input mechanisms which are the standard-rigid-base input model, the massless-foundation input model and the deconvolved-base-rock input model are used. The spatial variability of ground motion which is considered with the incoherence and wave-passage effects is taken into account in the analyses. The Izmit earthquake in 1999 is selected as a ground motion. Two-dimensional interface finite elements are used between the dam-soil deposit and asphalt face. The mean of absolute maximum values of displacements and stresses obtained from the three earthquake input models are compared with each other.
\end{abstract}

\section{Keywords}

Deconvolved acceleration; Interface finite element; Spatially varying ground motion; Asphaltic lining dam; Equivalent linear method

Received: 05 December 2018; Accepted: 12 December 2018

ISSN: 2630-5763 (online) C 2018 Golden Light Publishing ${ }^{\circledR}$ All rights reserved.

\section{Introduction}

The influence of the foundation soil conditions on the stochastic responses of the gravity damfoundation interaction systems is one of the conspicuous problems. The importance of the foundation interaction on the behavior of gravity dams subjected to earthquake ground motions has long been recognized [1] It is well known that asphaltic lining dams are soil-structure interaction problems. Therefore, dam-foundation interaction must be considered in the earthquake analysis of the dams. The different earthquake input mechanisms are used to consider the effect of the local soil conditions on the dynamic response of the damfoundation interaction systems [2]: The standardrigid-base input model (Model $\mathrm{A}$ ), the massless- foundation input model (Model B), the deconvolved-base-rock input model (Model C) and free-field dam-foundation interface input model (Model D).

In current practices, the analysis and design of structures due to the earthquake motions are based on the assumption that excitations at all the support points along the base are the same. This assumption, however, may be unrealistic for long structures, such as pipelines, bridges and embankment dams. Embankment dams extend for long distances along or close to the ground surface and earthquake ground motions can vary significantly over these distances. The spatial variation of ground motion arises from three main sources; the wave-passage effect results from the

\footnotetext{
* Corresponding author

E-mail: kemalhaciefendioglu@ktu.edu.tr
} 
difference in the arrival times of waves at different support points, the incoherence effect results from reflections and refractions of seismic waves through the soil during their propagation and the site-response effect arises from the differences in local soil conditions [3].

The dynamic solutions of earth and rock-fill dams have necessarily required nonlinear numerical techniques, which efficiently and accurately model the complex behavior of soil systems. One of the first studies where the material nonlinearity was taken into account was performed by Gazetas et al. [4] to estimate the nonlinear stochastic response of the fill dams subjected to earthquake ground motions. Several studies related with the stochastic dynamic analysis of nonlinear response of earth and rock fill dams taking into account the nonlinear characteristics of the dam material, was performed by $[4,5]$.

The aim of this paper is to investigate the influence of the foundation soil conditions on the stochastic responses of the Asphaltic lining damfoundation systems to stochastic seismic excitation. For this purpose, the spatially varying ground motion including the wave-passage and incoherence effects together by using the equivalent linear method is taken into account as an earthquake ground motion in this study. Twodimensional interface finite elements [6] are used between the dam soil deposit and asphaltic lining layer by being programmed in FORTRAN language by the author and incorporated into a general-purpose computer program for stochastic dynamic analysis structural systems to spatially varying ground motion.

\section{Equivalent linear method}

The equivalent linear analysis is performed in an iterative way. The strain properties of the materials are defined in each finite element member by a shear modulus and an equivalent damping ratio which depends on the shear strain. Initial estimates of shear modulus and damping ratio are given for each element at low-strain $\left(10^{-4} \%\right)$. With given values of shear modulus and damping ratio, a linear elastic analysis is performed to determine the stochastic dynamic response. An effective strain, which is usually considered as the maximum value for the stochastic analysis, is computed in each finite element member. It is noted that in establishing the effective strain it is not necessary to resort to arbitrary scaling of the computed strain values as is the case in the deterministic methods, where a strain reduction factor on the computed value of strain is applied. That is, the effective strain is used as the mean value of the random process describing the maximum value of the strain. Then the moduli and damping ratios are selected for the computed effective strain and used for the next iteration [4]. This procedure is repeated until the differences of moduli and damping ratios are very small between two iterations. The response value obtained at the last iteration is considered as the true nonlinear response.

The maximum dynamic shear modulus of cohesionless materials is computed using the following expression [7]

$\mathrm{G}_{\max }=1000\left(\mathrm{~K}_{2}\right)_{\max }\left(\sigma_{\mathrm{m}}\right)^{1 / 2}$

Values of $\left(\mathrm{K}_{2}\right)_{\max }$ (square-root of stress) determined by laboratory tests have been found to vary from 150-250 for compacted gravels and rockfill. Experimental data from the literature on shear strain dependent moduli and damping ratio for rock-fill (gravel) material are depicted Fig. 1(a-b), respectively [8]. Lastly, the variations of shear modulus and damping ratios with shear strain for rock material is shown in Fig. 2(a-b) [9].

\section{Earthquake input mechanisms}

The purpose of this paper is to estimate the stochastic response of an asphaltic lining damfoundation system subjected to different earthquake input mechanisms. These are the standard-rigid-base input model (Model A), the deconvolved-base-rock input model (Model B), the massless-foundation input model (Model C) and free-field dam-foundation interface input model (Model D). 
In the standard base input model (Model A), it is assumed that 2-D structures built on rock sites are supported by a large volume of deformable rock,

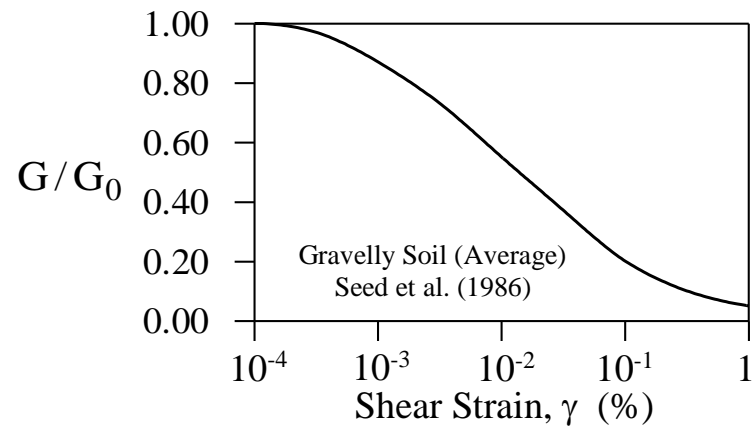

(a)

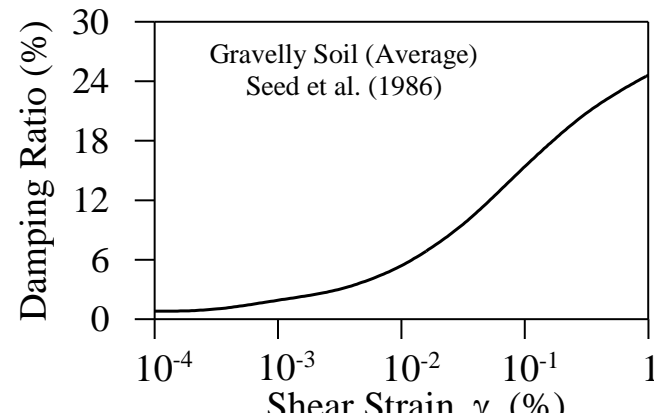

(b)

Fig 1. The variation of (a) shear modulus and (b) damping ratios for gravelly soil, respectively

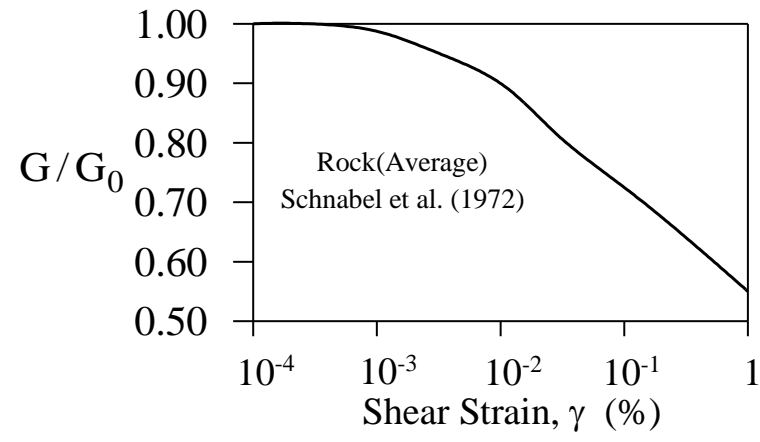

(a)

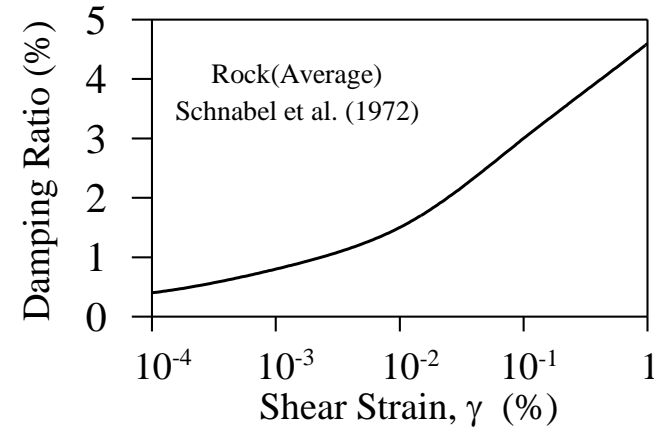

(b)

Fig 2. The variation of (a) shear modulus and (b) damping ratios for rock material, respectively

which in turn is supported by a rigid boundary. The seismic input in the form of response spectra or acceleration time-histories is defined as the motion of this rigid base, but it should be noted that the motions applied to the rigid base differ from the free-field motions recorded at ground surface. In the deconvolution base rock input model (Model B) approach, the recorded free-field surface motions are deconvolved to determine the motions at the rigid base boundary. The deconvolution analysis is performed on a horizontally uniform layer of deformable rock or soil deposits using the onedimensional wave propagation theory. For the soil sites, however, the strain-dependent nature of the nonlinear soil should be considered. The resulting rigid base motion is then applied at the base of the
2-D foundation structure system, in which the foundation model is assumed to have its normal mass as well as stiffness properties. The massless foundation rock model (Model C): An improved version of the model described in the standard base input model above is obtained by neglecting the mass of the deformable foundation region. In this case no wave propagation takes place through the foundation rock; thus, the prescribed motions at the rigid base are directly transmitted to the structure interface. This will eliminate the potential problem of artificial amplification of the free-field accelerogram. However, it has long been recognized that site effects can significantly affect the nature of strong ground motion. The obvious deficiency of Model A and Model C is that the 
motions actually occurring at the base of the soil layer cannot be the same as those recorded at its free surface. Accordingly, in the models a correction must be made to overcome this deficiency, either by calculation of a modified base rock motion by deconvolution of the free-field surface record (Model B) or by employing a formulation of the analysis procedure that applies the recorded accelerogram as a free-field input (Model D). Because both the deconvolved-baserock input (Model B) and free-field input (Model D) are applied to the same mathematical model consisting of a soil layer interposed between the foundation and the rigid rock base, and because the same free-field motion is assumed to exist at the surface of soil layer, both of these analysis procedures lead to the same results. For that reason, only the deconvolved-base-rock input model (Model B) will be used in this paper.

In the models, the site response effect is taken into account by that the dam foundation regions are modeled by using the finite element method. In the upstream region, the foundation is considered as medium soil which this region is modeled as alluvium material, whereas in the downstream region, the foundation is considered as firm soil which this region is modeled as rock material.

\section{Random vibration formulation}

Since the formulation of the random vibration theory for spatially varying ground motion is given previously by many researchers $[5,10]$, in this study only required final equations will be considered. The random vibration theory provides an approximate estimate of the mean of the absolute maximum response of the structure in terms of the power spectral density function and a coherency function. The free response can be decomposed into pseudo-static and dynamic parts, i.e., $\mathrm{z}=\mathrm{z}_{\mathrm{s}}+\mathrm{z}_{\mathrm{d}}$ when there is a differential excitation at the supports. Assuming the stationary excitation, the total variance responses can be obtained from

$\sigma_{\mathrm{z}}^{2}=\sigma_{\mathrm{z}_{\mathrm{d}}}^{2}+\sigma_{\mathrm{z}_{\mathrm{s}}}^{2}+2 \operatorname{Cov}\left(\mathrm{z}_{\mathrm{s}}, \mathrm{z}_{\mathrm{d}}\right)$

in which $\sigma_{z_{d}}^{2}$ and $\sigma_{z_{s}}^{2}$ are the dynamic and pseudo- static variances, respectively, and $\operatorname{Cov}\left(\mathrm{z}_{\mathrm{s}}, \mathrm{z}_{\mathrm{d}}\right)$ is the covariance between the dynamic and pseudo-static responses $\mathrm{z}_{\mathrm{d}}$ and $\mathrm{z}_{\mathrm{s}}$ [3].

Depending on the peak response and standard deviation $\left(\sigma_{z}\right)$ of $\mathrm{z}(\mathrm{t})$ the mean of maximum value, $\mu$, in the stochastic analysis can be expressed as

$\mu=p \sigma_{\mathrm{z}}$

in which $p$ is a peak factor, which is a function of the time of the motion and the mean zero crossing rate [11].

\section{Spatially varying ground motion}

The spatial variability of the ground motion is characterized with the coherency function $\gamma_{1 \mathrm{~m}}(\omega)$. The cross-power spectral density function between the accelerations $\ddot{\mathrm{u}}_{\mathrm{g}_{\mathrm{l}}}$ and $\ddot{\mathrm{u}}_{\mathrm{g}_{\mathrm{m}}}$ at the support points $l$ and $m$ is written as

$\gamma_{l m}(\omega)=\frac{S_{\ddot{u}_{g_{l}} \ddot{u}_{g_{m}}}(\omega)}{\sqrt{S_{\ddot{u}_{g_{l}} \ddot{u}_{g_{l}}}(\omega) S_{\ddot{u}_{g_{m}}} \ddot{u}_{g_{m}}(\omega)}}$

in which $S_{\ddot{u}_{g_{1}}} \ddot{g}_{g_{1}}(\omega)$ and $S_{\ddot{u}_{g_{m}}} \ddot{u}_{g_{m}}(\omega)$ indicate the auto-power spectral density functions of the accelerations at the support points 1 and $\mathrm{m}$ for surface and base of the foundation (deconvolved ground motion), respectively.

Recently, Der Kiureghian [12] proposed a composite model of the coherency function is

$\gamma_{l \mathrm{~m}}(\omega)=\gamma_{\operatorname{lm}}(\omega)^{\mathrm{i}} \exp \left[\mathrm{i}\left(\theta_{\operatorname{lm}}(\omega)^{\mathrm{w}}+\theta_{\operatorname{lm}}(\omega)^{\mathrm{s}}\right]\right.$

in which, $\gamma_{\operatorname{lm}}(\omega)^{\mathrm{i}}$ characterizes the incoherence effect, $\gamma_{\operatorname{lm}}(\omega)^{\mathrm{w}}$ represents the wave passage effect, and $\gamma_{\operatorname{lm}}(\omega)^{\mathrm{s}}$ defines the complex valued site response effect, respectively. For the incoherence effect, the model based on the statistical analysis of strong ground motion data from the SMART-1 dense array and developed by Harichandran and Vanmarcke [10] is considered. 


\section{Application}

Muratli Dam is selected as the asphaltic lining damfoundation interaction problem, which is located in Artvin in Turkey. A typical dam cross section has a height of 44.0 meters above the base. The crest has a width of 10.0 meters and a maximum length of the dam itself of 213.0 meters. Upstream and downstream slopes are at 2:1. The dam itself and foundation block are included together in the analyses. The height and length of the foundation block is 61.5 and 245.0 meters, respectively. In the upstream region, the foundation is considered as alluvium material, whereas in the downstream region, the foundation is considered as rock material. Fig. 3 shows the cross section at midlength of the dam-foundation interaction system. The properties of the dam-foundation systems and interface elements are given in Table 1. $\left(\mathrm{K}_{2}\right)_{\max }$ factor given in Eq. (1) is selected as 170 and 220 at small-strains for the dynamic modulus coefficient of the rock-fill and alluvium (sand and gravel) materials, respectively. The initial damping value is selected as $5 \%$ for the stochastic analysis of nonlinear response of the asphaltic lining damfoundation system.

The finite element model consists of 161 three and four-node isoparametric finite elements and interface finite element for the dam-foundation system as shown in Fig. 4. The nodes representing the extreme left and right sides of the foundation block were allowed a horizontal degree of freedom.

\section{Ground motion record}

The stochastic analysis is performed to estimate the deconvolved ground motion effect on the nonlinear response of the Muratli Dam for spatially varying earthquake ground motion by taking into account the incoherence effect, wave passage effect and site response effect which is taken into account by that the foundation is modeled by using finite element method according to soil type.

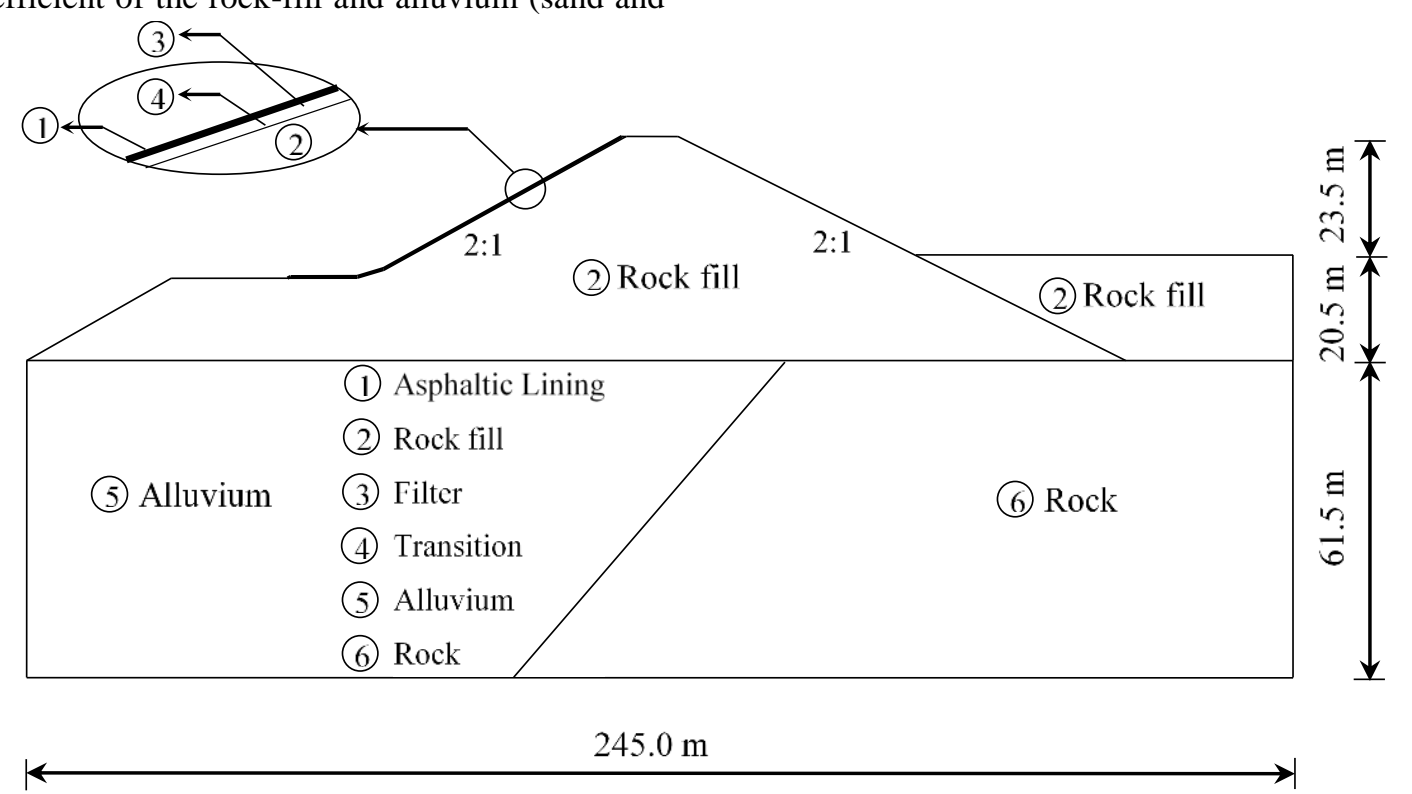

Fig 3. The dimensions and materials of the dam-foundation interaction system

Table 1. Material properties for A-A cross section of the Muratli Dam

\begin{tabular}{lccc}
\hline Materials & $\begin{array}{c}\text { Modulus of Elasticity } \\
\left(\mathrm{N} / \mathrm{m}^{2}\right)\end{array}$ & $\begin{array}{c}\text { Poisson's } \\
\text { Ratio }\end{array}$ & Unit weights $\left(\mathrm{kN} / \mathrm{m}^{3}\right)$ \\
\hline Rockfill & From Eq.(1) & 0.35 & 21.50 \\
Foundation (Alluvium) & From Eq.(1) & 0.40 & 21.00 \\
\hline
\end{tabular}




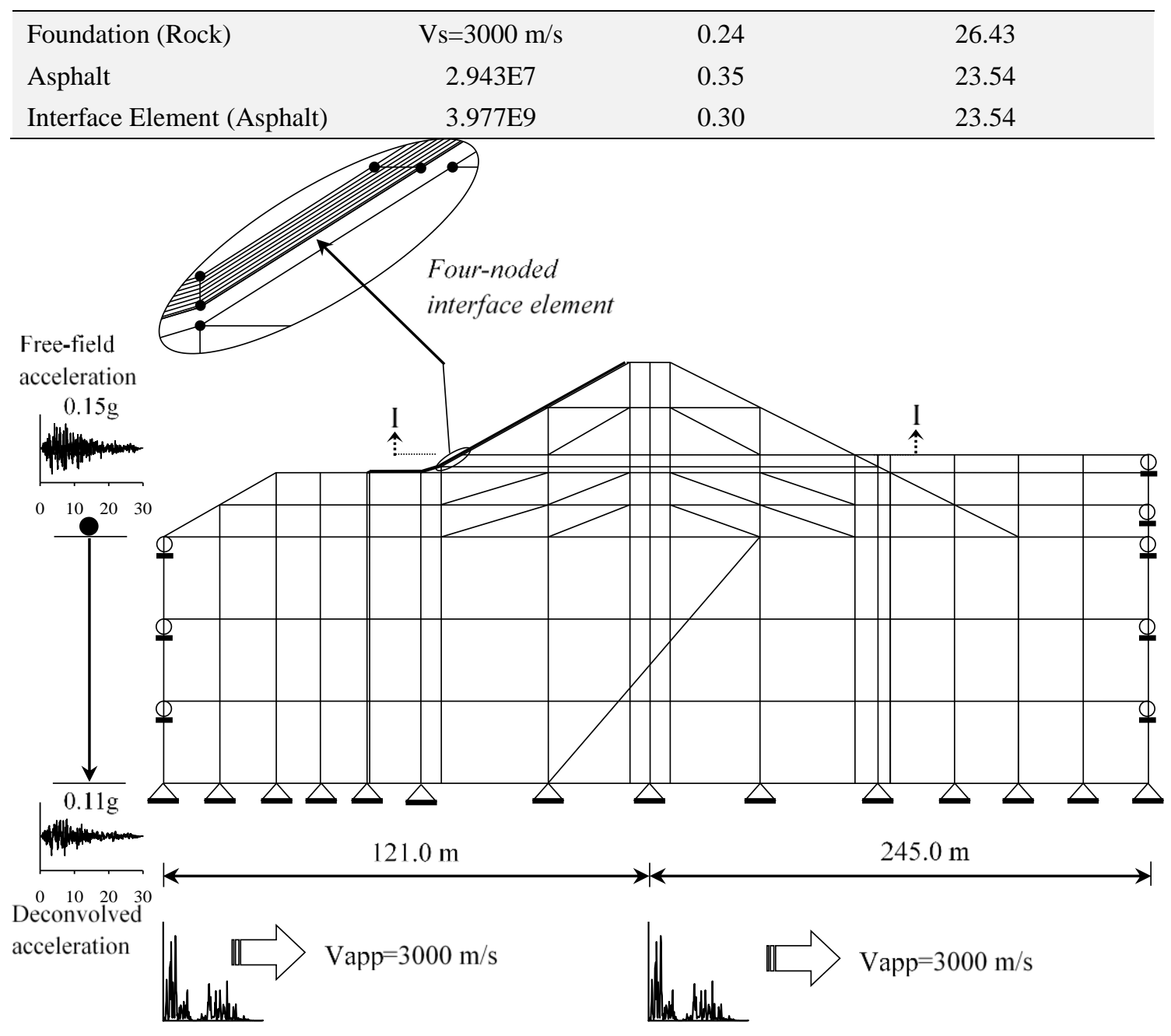

Fig 4. The finite element model of the dam-foundation interaction system and deconvolved-base-rock input model

For this purpose, Izmit earthquake in 1999 is considered in the analyses for the dam-foundation interaction system supports. The time history and the power spectral density function of free-surface ground motion are plotted in Figs. 5(a)-(b), respectively.

The deconvolved accelerogram of the ground motion is calculated by using the computer program SHAKE91 [13], which is based on the one-dimensional wave propagation theory. The principal parameters in the analysis of deconvolved accelerogram are the shear wave velocity and the damping ratio of the foundation soil. It should be noted that the accelerogram are affected by the shear wave velocity and the damping ratio of the foundation soil. The artificial amplification occurs with increasing the flexibility of the foundation soil. The values of the shear wave velocity and the damping ratio of the foundation rock are selected as $3000 \mathrm{~m} / \mathrm{s}$ and $10 \%$, respectively. The time history and the power spectral density function of the deconvolved ground acceleration are shown in Figs. 6(a)-(b), respectively. It can be seen from the Figs. 6 that the local soil conditions considerably affect the frequency contents and amplitudes of the power spectral density functions of the ground acceleration record and deconvolved values become smaller than the values recorded at the free surface. 


\section{Numerical results}

In order to investigate the effects of earthquake input mechanisms on the nonlinear behavior of the asphaltic lining dams subjected to spatially varying

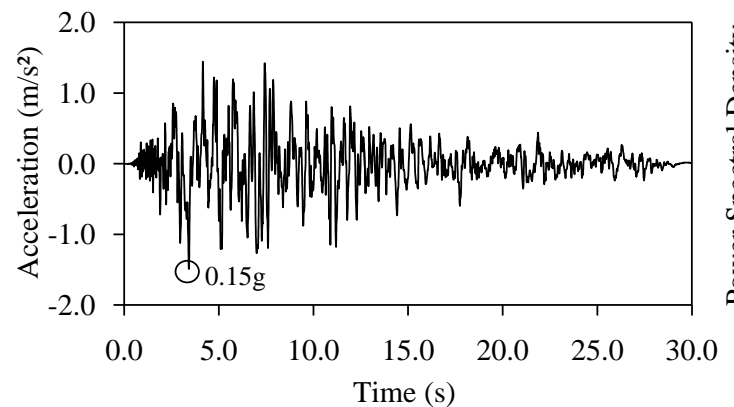

(a) ground motion, the displacements and stresses on the selected section are computed. The mean of maximum values of the stationary responses are calculated for three-earthquake input mechanisms

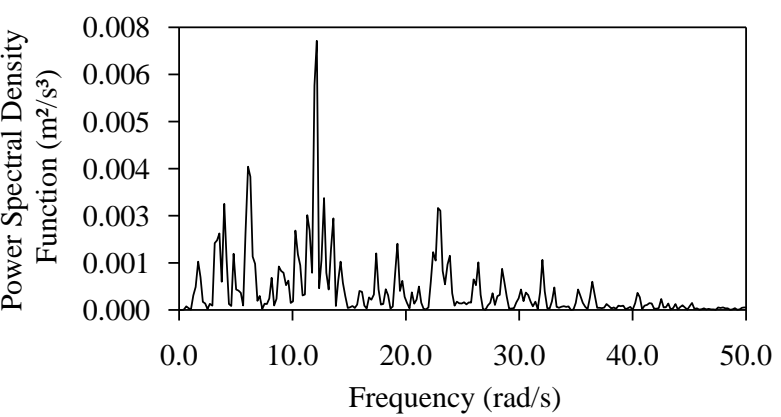

(b)

Fig 5. (a) The time-histories and (b) power spectral density function of free-surface ground acceleration

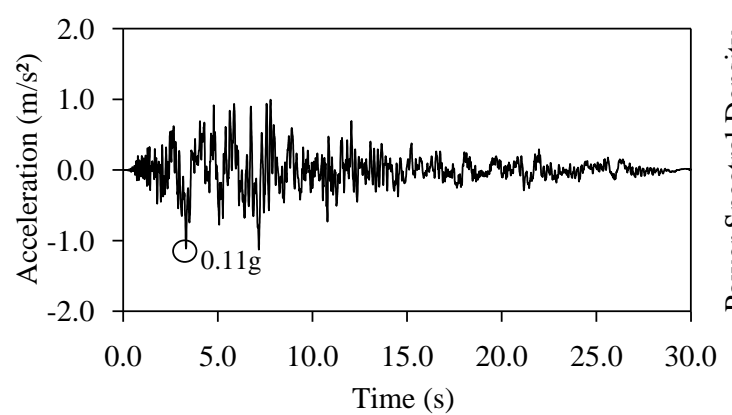

(a)

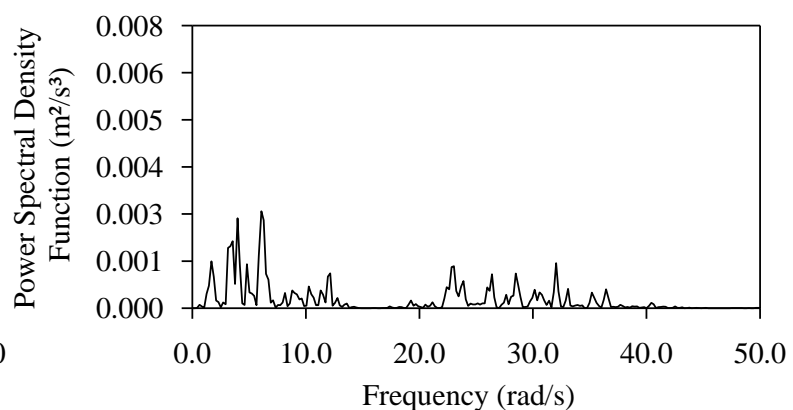

(b)

Fig 6. (a) The time-histories and (b) power spectral density function of deconvolved ground acceleration

which are the standard-rigid-base input model (Model A), the deconvolved-base-rock input model (Model B) and the massless-foundation input model (Model C). While the power spectral density function determined at the free surface ground acceleration (Fig. 5(a)) is used for Model A and Model $\mathrm{C}$, those at the deconvolved ground acceleration (Fig. 6(a)) is used for Model B. For the incoherence effect, Harichandran and Vanmarcke's model [10] is used. Soil conditions are considered as homogeneous throughout the study. The spatially varying ground motion is applied to the dam-foundation systems in the horizontal direction as shown in Fig.4. The apparent wave velocity is taken as Vapp $=3000 \mathrm{~m} / \mathrm{s}$ for the rock material. The duration of the earthquake ground motions applied to the dams is taken as 30.0 seconds.

The mean of absolute maximum horizontal displacements and stresses obtained on Section I-I of the dam are shown in Fig. 7 and Figs. 8-10 for three earthquake input mechanisms. The mean of absolute maximum horizontal displacements and stresses obtained on Section II-II of the dam are also presented in Fig. 11 and Figs. 12-14 for three earthquake input mechanisms. These figures show that Model A induce the largest values when compared those of Model B and Model C. The results derived from Model B are the smallest. The mean of absolute maximum stress values are calculated at the centre of points of the elements. It is observed from the figures that the stress values obtained from the deconvolved-base-rock input model (Model B) and the massless-foundation input model (Model C) are generally closer to each other while the standard-rigid-base input model (Model A) produces the largest response. The deconvolved-base-rock input model (Model B) yields the smallest values. 


\section{Conclusions}

In this paper, influence of soil conditions on nonlinear dynamic response of an asphaltic lining dam-foundation interaction system to spatially varying ground motion including the wavepassage, incoherence and site response effects together is determined by using the equivalent linear method. For this purpose, three different

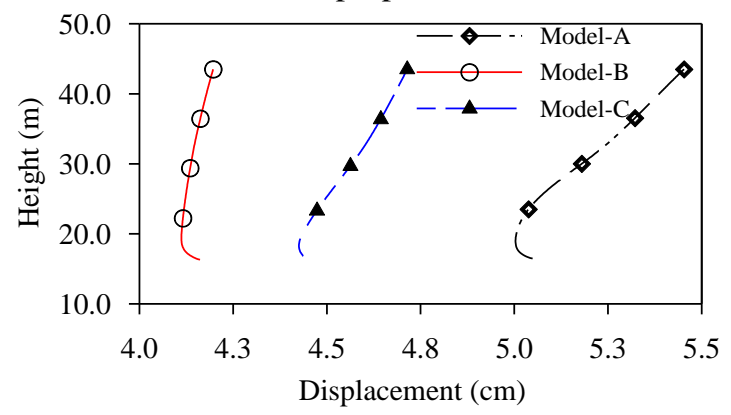

Fig 7. Mean of absolute maximum horizontal displacements on Section I-I

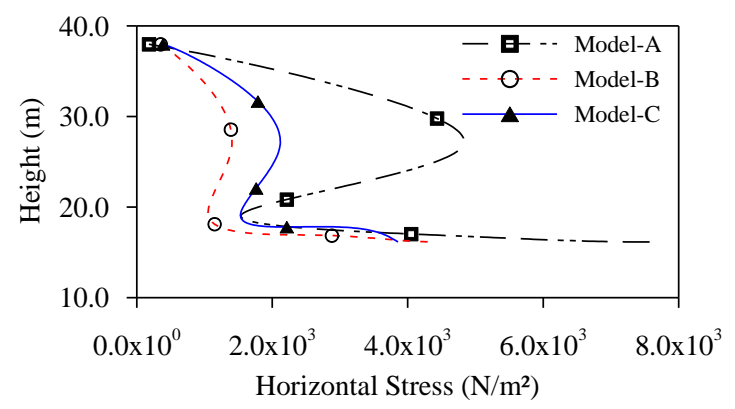

Fig 8. Mean of absolute maximum horizontal stresses on Section I-I

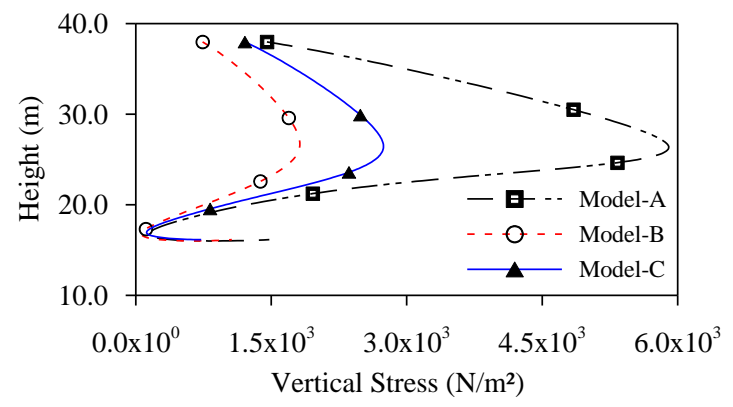

Fig 9. Mean of absolute maximum vertical stresses on Section I-I

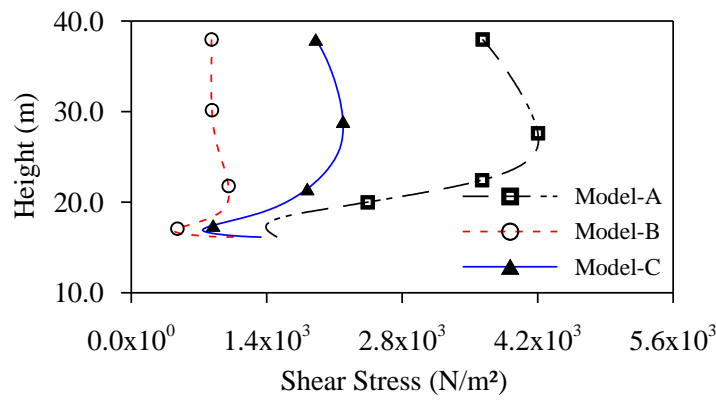

Fig 10. Mean of absolute maximum shear stresses on Section I-I

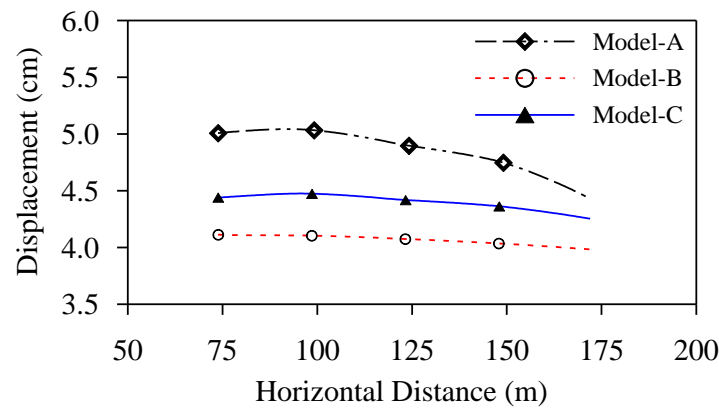

Fig 11. Mean of absolute maximum horizontal displacements on Section II-II

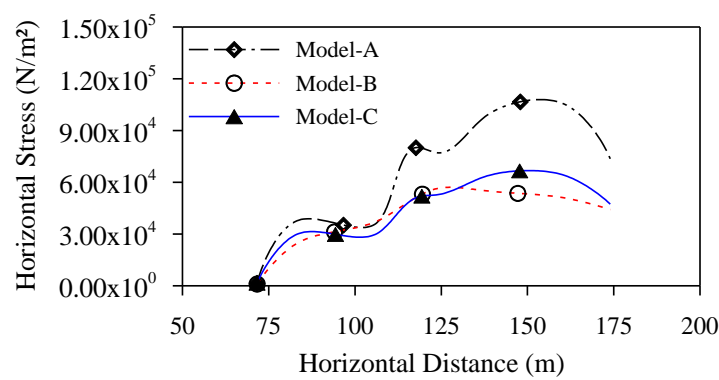

Fig 12. Mean of absolute maximum horizontal stresses on Section II-II

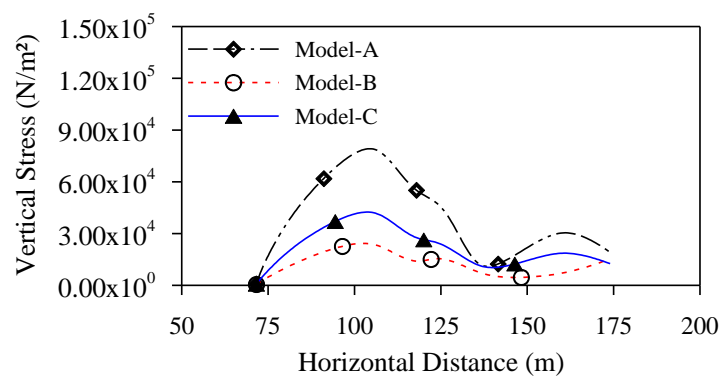

Fig 13. Mean of absolute maximum vertical stresses on Section II-II 


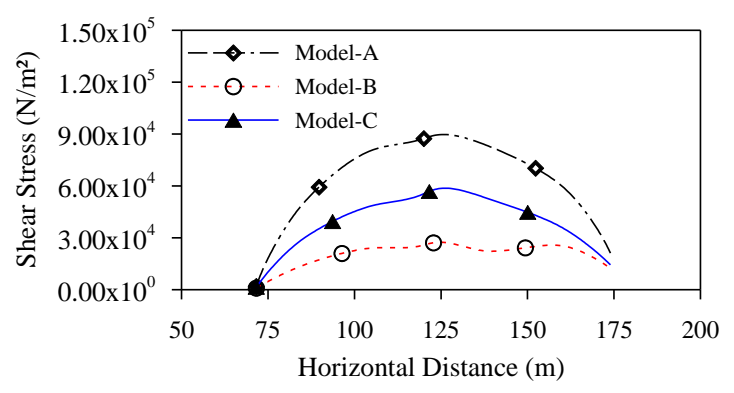

Fig 14. Mean of absolute maximum shear stresses on Section II-II

earthquake input mechanisms which are the standard-rigid-base input model (Model A), the deconvolved-base-rock input model (Model B) and the massless-foundation input model (Model C) are used.

The results obtained from the application of the three earthquake input mechanisms to an asphaltic lining dam-foundation system, are clearly shown that the use of different input models occurs significant differences in the structural response of this type of structure. The standard-rigid-base input model (Model A) yields the very significant amplification in the displacements and the stress values when compared with the other models (Model B and Model C). Therefore, the standardrigid-base input model (Model A) is inadequate to evaluate the nonlinear dynamic response of asphaltic lining dam-foundation system and should not be used in practice. So, it can be concluded that the deconvolved-base-rock input model (Model B) can most properly represent the nonlinear performance of the asphaltic lining dam-foundation systems to spatially varying earthquake ground motion.

\section{References}

[1] Chopra AK, Chakrabarti P (1981) Earthquake analysis of concrete gravity dams including damwater-foundation rock interaction. Earthquake Engineering \& Structural Dynamics 9(4): 363-383.

[2] Leger P, Boughoufalah M (1989) Earthquake input mechanisms for time-domain analysis of damfoundation systems. Engineering Structures 11(1): $37-46$

[3] Chen MT, Harichandran RS (2001) Response of an earth dam to spatially varying earthquake ground motion. Journal of Engineering Mechanics 127(9). 932-939.

[4] Gazetas G, DebChaudhury A, Gasparini DA (1982) Stochastic estimation of the nonlinear response of earth dams to strong earthquakes. International Journal of Soil Dynamics Earthquake Engineering 1(1): 39-46.

[5] Haciefendioglu K (2006) Transient stochastic analysis of nonlinear response of earth and rock-fill dams to spatially varying ground motion. Structural Engineering and Mechanics 22(6).

[6] Coutinho ALGA, Martins MAD, Sydenstricker RM, Alves JLD, Landau L (2003) Simple zero thickness kinematically consistent interface elements. Computers and Geotechics 30(5): 347374.

[7] Seed HB, Idriss IM. Soil moduli and damping factors for dynamic response analyses. California University, Berkeley. Earthquake Engineering Research Center, 1970.

[8] Seed HB, Wong RT, Idriss IM, Tokimatsu K (1986) Moduli and damping factors for dynamic analyses of cohesionless soils. Journal of Geotechnical Engineering 112(11): 1016-1032.

[9] Schnabel PB, Lysmer J, Seed HB (1972) SHAKE, A computer program for earthquake response analysis of horizontally layered sites. Report No EERC 72-12, University of Caliornia, Berkeley, 1972.

[10] Harichandran RS, Vanmarcke EH, Stochastic variation of earthquake ground motion in space and time. Journal of Engineering Mechanics 112(2): 154-174.

[11] Der Kiureghian A (1980) Structural response to stationary excitation. Journal of Engineering Mechanics Division 106(6): 1195-1213.

[12] Der Kiureghian A (1996) A coherency model for spatially varying ground motions. Earthquake Engineering \& Structural Dynamics 25(1): 99-111.

[13] Idriss IM, Sun JI. User's manual for SHAKE91 : a computer program for conducting equivalent linear seismic response analyses of horizontally layered soil deposits. Davis California: Center for Geotechnical Modeling Dept. of Civil and Environmental Engineering University of California Davis, 1993. 